\title{
A Panoramic View of Blood and Blood Product: Use in the Past Half Century
}

\author{
Charles E Lucas
}

\begin{abstract}
Background: Many changes regarding the use of blood and blood products for resuscitation of severely injured patients have occurred in the past 50 years. This study presents these changes.
\end{abstract}

Study design: A review of resuscitation regimens over 50 years is presented.

Results: During the 1960s, hemorrhage shock (HS) was treated with whole blood (WB) and balanced electrolyte solution (BES); fresh WB restored the labile factors (FV and FVIII) during massive transfusion (MT). When component therapy with red cells (RBC) was started, plasma (FFP) had to be added; patients with $\mathrm{MT}$ received a 2/5 RBC/FFP ratio. Platelets were reserved for oozing or counts below 50,000. During the Vietnam conflict, many recommended supplemental albumin therapy. A large prospective randomized study showed that albumin therapy caused many adverse effects including coagulopathy. During the 1980s, the National Institute of Health (NIH) responded to a shortage of FFP by initiating a consensus development conference (CDC) which concluded that FFP was not indicated without an established coagulopathic bleeding; animal HS models showed FFP was beneficial. During the 1990s, military surgeons recommended a $1 / 1 \mathrm{FFP} / \mathrm{RBC}$ ratio. Studies, herein, demonstrated that a $0.3 / 1 \mathrm{FFP} / \mathrm{RBC}$ ratio effectively restored procoagulants; whereas, ratios above $0.45 / 1$ FFP/RBC caused increased BES needs and longer stays.

Conclusion: Initial therapy for HS should be BES followed by $\mathrm{RBC}$ to maintain hemoglobin, perfusion and urine output. FFP should be supplemented after 5 units RBC using a 0.5 FFP/ RBC until hemostasis is obtained. Platelets should be added for 'medical' oozing and thrombocytopenia.

Keywords: Transfusion, Blood component therapy, Traumatic coagulopathy, Resuscitation.

How to cite this article: Lucas CE. A Panoramic View of Blood and Blood Product: Use in the Past Half Century. Panam J Trauma Critical Care Emerg Surg 2012;1(3):139-145.

Source of support: Nil

Conflict of interest: None declared

\section{RESUMEN}

Antecedentes: Se han producido muchos cambios con respecto al uso de sangre y hemoderivados para la reanimación de pacientes con lesiones graves en los últimos 50 años. Este estudio presenta estos cambios.

Diseño del estudio: Se presenta una revisión de los regímenes de reanimación de hace más de 50 años.

Resultados: Durante la década de los 60, el Shock Hemorrágico (SH) se trató con sangre entera (SE) y solución electrolítica isotónica (SEI); la SE fresca restauraba los factores lábiles (FV y FVIII) durante la transfusión masiva (TM). Cuando la terapia de componentes de glóbulos rojos (GR) fue iniciada, se tuvo que agregar plasma (FFP); pacientes con TM recibieron una proporción GR/FFP de $2 / 5$. Las plaquetas fueron reservadas para sangrados graduales o conteos por debajo de cincuenta mil. Durante el conflicto de Viet Nam, muchos recomendaron la terapia con suplementación de albúmina. Un gran estudio prospectivo randomizado mostró que el tratamiento con albúmina provoco muchos efectos adversos, incluyendo coagulopatía. Durante la década de los 80 el Instituto Nacional de Salud $(\mathrm{NIH})$, respondió a la escasez de FFP, iniciando una Conferencia para desarrollar un Consenso (CDC), que concluyó que la FFP no era indicada sin un sangrado coagulopático establecido; modelos animales con SH mostraron que FFP era beneficioso. Durante la década de los 90 , los cirujanos militares recomendaban una proporción FFP/GR de 1/1. Estudios, aquí, demostraron que una proporción FFP/GR de 0.3/1 restauraba eficazmente a los procoaugulantes, mientras que una proporción FFP/GR de $0.45 / 1$ provocaba un aumento de las necesidades de SEI y una estancias hospitalaria prolongada.

Conclusiones: La terapia inicial para SH debería ser SEI seguida por GR para mantener la hemoglobina, perfusión y la producción de orina. EI FFP debe ser administrado después de 5 unidades de glóbulos rojos con un FFP/GR de 0,5 hasta obtener la hemostasia. Las plaquetas deben ser agregadas para sangrados graduales 'médicos' y trombocitopenia.

Palabras claves: La transfusión, Terapia de componentes sanguíneos, Coagulopatía traumática, Reanimación.

\section{INTRODUCTION}

During the past half-century, there have been many changes in the use of blood and blood products in the treatment of severely injured patients with hemorrhagic shock. These changes reflect ongoing improvements in the science of blood coagulation, the application of new policies by the blood banking industry and the result of ongoing clinical experiences. This treatise highlights these changes leading to the author's recommended guidelines for treating seriously injured patients.

\section{Resident Years}

When the author was a young resident in the early and mid-1960s, the treatment for severely injured patients with hemorrhagic shock included whole blood (WB) and balanced electrolyte solution (BES). Sodium bicarbonate was routinely added to neutralize the acidosis due to hemorrhagic shock; calcium was added to treat hypocalcemia. ${ }^{1,2}$ When patients required a massive transfusion (MT) of more than ten units of blood during the combined emergency room and operating room resuscitation period (phase I), coagulopathy was a threat because most of the WB transfusions were more 
than seven days old and some exceeded 20 days in age. Old blood was known to be deficient in the labile factors, namely factor V (FV) and factor VIII (FVIII). Thus, fresh WB was used to counter this MT induced coagulopathy. When no fresh blood was available, a pool of walking donors was tapped in order to restore FV and FVIII. When no walking donors were available, family members were called upon to donate blood to their loved ones. If necessary, the donor relative would lie next to the coagulopathic patient in the postoperative recovery room as the fresh blood ran from donor into the patient. During these years, the acquired immune deficiency syndrome was unknown and the risk of transfusing hepatitis $\mathrm{C}$ was under appreciated. An unwritten MT policy evolved. When a patient received five or less WB transfusions, coagulopathy was never an issue. ${ }^{3}$ Patients who developed so-called medical bleeding, as determined by oozing at previously dry sites, almost uniformly had a platelet count less than 50,000. The need for platelet transfusion became evident, when oozing persisted despite fresh WB and the platelet count was less than $50,000 .^{3}$

\section{Young Attending}

Beginning in 1967, the author became the prime attending surgeon on the huge emergency surgical service at Detroit Receiving Hospital. This service provided care for all types of emergencies which, of course, included severe injuries in patients requiring MT. Concomitantly, the Wayne State University Department of Physiology was a national leader in coagulation research. This opportunity for synergistic coagulation research was unparalleled as the author became an associate member of this department.

\section{Disseminated Intravascular Coagulation}

During these years, the syndrome of disseminated intravascular coagulation (DIC) was popularized. ${ }^{4,5}$ DIC was characterized by refractory oozing following massive transfusion and was associated with thrombocytopenia, hypofibrinogenemia and abnormal clotting times, including the prothrombin time and partial thromboplastin times. ${ }^{6,7}$ The etiology was obscure but sepsis was a common element. Treatment included support plus heparinization in order to break the cycle of diffuse fibrin deposition. ${ }^{6,8}$ During these years, the author treated many such patients with heparin. The mortality rate was $100 \%$. An interesting anecdote resulted. The highly esteemed chairman of the department, Dr Alexander J Walt, a founding member of the PanAmerican Trauma Society, learned that his young faculty member was no longer following the recommendations from the coagulation team to administer heparin. The young author confessed this lack of compliance to Dr Walt claiming to have killed more Michiganians by heparinizing patients with DIC than anybody in the Michigan prison system; the young author offered to transfer such patients to the chairman's service. Fortunately, Dr Walt believed his young faculty member and the killing of patients thought to have DIC by administering heparin stopped immediately.

\section{Component Therapy}

During the early 1970s, the American Blood Banking Association (ABBA) moved fairly rapidly toward component therapy. Consequently, access to WB and fresh WB became limited. The transition from administering fresh WB to patients with coagulopathy after MT to the administration of component therapy, namely, fresh frozen plasma (FFP) was not always smooth. These patients were now routinely receiving packed red blood cells (PRBCs) which have none of the procoagulants. Consequently, patients receiving MT would necessarily have to receive FFP. Since this was a new therapy, it was not known how much FFP should be administered and when it should be administered. This led to a learning process where, by trial and error, new guidelines were developed. These guidelines were based upon the clinical status of the patient, the responses to supplemental FFP therapy, and the readily available measurements of the standard coagulation tests, namely, the prothrombin time (PT), the partial thromboplastin time (PTT), the thrombin time (TT), and platelet function as determined by platelet count, bleeding time and platelet release factor measurements. ${ }^{10,11}$

Based upon extensive clinical experience, patients with less than five units RBC were found to not require FFP supplementation. When patients were started on a sixth RBC transfusion and bleeding was not controlled, FFP supplementation was begun utilizing two units of FFP for every five units of RBC. ${ }^{11}$ Platelet counts and platelet function were monitored but platelet supplementation was not initiated unless the platelet count was less than 50,000. Platelet transfusions were rarely used during the emergency room and operative room resuscitation. ${ }^{10}$

\section{Modified Whole Blood}

During these same years, Heinback et al from the great State of Washington adapted to the ABBA regimen of component therapy by using modified whole blood (MWB). ${ }^{12}$ The MWB was prepared by separating the platelets and cryoprecipitate from newly donated blood, thereby, preserving the coagulation factors normally present in FFP. MWB therapy was popular in Washington and some of the nearby northwestern states but was not employed in the Midwestern part of America or in Detroit. The author suspects that the lack of adaptation of this very reasonable and logical approach to component therapy was driven by financial considerations. 


\section{Colloid Therapy and Coagulopathy}

During the United States involvement in the Vietnam conflict, divergent views evolved regarding the optimal treatment for injured soldiers. A large contingent of resuscitating physicians followed the principle developed by Tom Shires et al that there should be a 3:1 ratio BES to $\mathrm{RBC}$, when resuscitating the severely injured patient from hemorrhagic shock. ${ }^{13,14}$ A separate contingent concluded that the resuscitation with large volumes of BES was detrimental due to the resultant reduction in effective colloid pressure, thereby, facilitating the extravascular movement of fluid, especially into the lungs. ${ }^{15,16}$ This great controversy spread to the United States where many, particularly the companies that made albumin, recommended colloid supplemented resuscitation.

During the mid-1970s, the author instituted a prospective randomized study on the effects of albumin supplementation to the standard resuscitation regimen in patients with severe injury requiring MT. ${ }^{17,18}$ Both groups received $\mathrm{RBC}$ and FFP per established guidelines; the colloid supplemented patients received additional albumin, whereas the control patients received, by random selection, only the BES. This was the largest prospective randomized study of severely injured patients requiring MT for severe injury. This study demonstrated that the albumin supplemented patients suffered many detrimental effects, including a prolonged PT, PTT and a reduction in fibrinogen levels compared to the BES patients. ${ }^{19,20,21}$ These studies in man suggested that the albumin supplemented patients had an oncotically driven movement of coagulation factor proteins out of the plasma into the interstitial space, where they were no longer available to support intravascular coagulation. ${ }^{22,23}$ These suspicions were later confirmed in controlled canine models. $^{24}$

\section{FFP Crisis}

The marked increase in the use of FFP to protect against coagulopathy in patients requiring MT created a crisis in the United States; there was not enough FFP to supply all demands. The 500 fold rise in FFP utilization during the early 1980s stimulated the initiation of a CDC by the National Institute of Health. The author, along with one other surgeon, served on the planning committee. During the breakfast session prior to the first meeting, the author overheard other members of the committee stating that there are some physicians in America who actually recommend the prophylactic administration of FFP before documentation of a prolongation of the PT, PTT or TT. The author, who had been recommending the prophylactic administration of FFP for the previous 15 years, confessed. Despite the opinions by the author, the CDC concluded that FFP was being overused and it should be restricted to only those patients who have an established coagulopathy as evidenced by a PT three seconds over control or a PTT beyond 1.5 times normal. ${ }^{25}$ No decision was made regarding the level of TT on the use of FFP supplementation.

\section{First Canine Study}

After being chastised by the other members of the CDC, the author returned to Detroit and initiated a canine study in which animals subjected to a severe hemorrhagic shock insult were resuscitated with RBCs, BES and fresh, nonfrozen plasma or additional BES by random selection. All of the ABBA guidelines for blood donation, storage and replacement therapy were followed. Serial measurements were made of vital signs, hemoglobin, coagulation tests, platelets and platelet function, and most of the procoagulants. The results showed that there were no statistically improved benefits from supplemental fresh plasma compared to those animals that, by random selection, received no fresh plasma. $^{26}$

\section{A Clinical Disaster}

Stimulated by the CDC conclusions and the lack of significant benefit in the two canine groups, a new policy of treating severely injured patients with hemorrhagic shock and receiving MT was initiated. ${ }^{27,28}$ This study included only those patients treated by the author. FFP supplementation was restricted to patients meeting the CDC guidelines. A number of these patients, therefore, did not receive FFP during operation because the intraoperative coagulation studies were normal. Some of these patients, in the early postoperative period, developed obvious coagulopathic bleeding associated with hypotension and the need for rapid replacement with RBCs and FFP in addition to BES. During a short interval of no more than three months, there were at least two preventable deaths in patients thought to have injuries compatible with survival.

\section{Second Canine Study}

Clearly, there were differences between the patients who developed postoperative coagulopathy and the results suggested by the initial canine study ${ }^{28}$ This lead to a second canine study designed to better imitate the clinical setting. ${ }^{27}$ The two groups of animals were subjected to the same severe hemorrhagic shock insult with the one group, by random selection, receiving fresh plasma and the other group receiving only supplemental BES. Following the resuscitation, a one-hour exchange period was instituted, whereby, both groups of animals would continue to have 
blood letting with a normal blood pressure while continued RBC transfusion was given at a rate to keep the blood pressure normal. This was thought to represent the clinical situation, where a patient had been stabilized during the early part of operation but bleeding had not yet been controlled so that blood loss continued and blood was infused by the anesthesiology team. One group of animals received RBCs and BES while the other group also received fresh plasma. This study demonstrated, by the end of the onehour exchange period, there were significant reductions in all of the procoagulants with the exception of factor VII, the smallest procoagulant. There were also changes in platelets and platelet function. Clearly, the second study re-established the importance of FFP supplementation provided prophylactically in patients requiring MT before the development prolongation of the clotting times or abnormal platelet function. The results of this study led to a reinstitution of the prior protocol, whereby severely injured patients requiring more than five transfusion RBCs would have supplemental FFP at the rate of about 2 units FFP for every 5 units RBCs. Sequential measurements were made of coagulation factors and platelet function through the postoperative period to determine the need for additional FFP therapy. ${ }^{28}$ These clinical studies demonstrated that the $1: 4 \mathrm{FFP} / \mathrm{RBC}$ ratio was sufficient in restoring procoagulants to the vast majority of patients with hemorrhagic shock requiring MT. This regimen of resuscitation continued through the rest of the 1980s and into the first portion of the 1990s.

\section{Recombinant Factor VIla}

The next challenge to this resuscitation regimen arose when Bufford et al suggested, on the basis of a random multinational trial, that recombinant factor VIIa (FVIIa) reduced coagulopathy and improved survival in severely injured patients after blunt injury. ${ }^{29}$ There were no statistical differences in those patients that received FVIIa after penetrating wounds but there was a significant improvement in those patients who had sustained blunt injury. The amounts of FVIIa were astronomical in view of the very small amounts of FVII that are needed to institute the FVIIa component of the extrinsic pathway. ${ }^{30}$ The results of this study seemed illogical to the author since the in vivo concentration of unactivated FVII is about $5 \mathrm{pmol} / \mathrm{L}$ and this remains the same after cleavage which is brought about by separating of the ARG152-ILE153 bond; this does not reduce the total amount of FVII. ${ }^{31}$ Likewise, the second controlled canine study (described above) showed a significant difference in all of the procoagulants with the exception of FVII animals that received fresh plasma as opposed those that received only BES. ${ }^{27}$ The lack of correlation between the Bufford results on patients with blunt injury and the lack of significant changes in animals with hemorrhagic shock raised the question in the author's mind as to whether the clinical patients reported by Bufford et al were resuscitated with a fluid which contained supplemental colloid. If, indeed, colloid was used in their resuscitation, then the addition of FVIIa would likely be beneficial since the innate FVII would be driven into the extravascular space by the colloid. Bufford et al never defined the resuscitation fluids. ${ }^{29}$ Subsequent clinical studies have not demonstrated any benefit to adding FVIIa to the resuscitation regimen. ${ }^{32,33}$ The author has to plead ignorance regarding any clinical benefits of FVIIa, having never felt a need for its administration.

\section{Military Resuscitation}

During the late 1990s and early twentieth century, our military colleagues working in Iraq and Afghanistan promoted a hemostatic resuscitation regimen of $1 \mathrm{FFP} / 1$ $\mathrm{RBC} / 1$ platelet. ${ }^{34,35}$ These recommendations were based upon their findings that patients receiving a lower FFP/RBC ratio had a higher mortality rate. These recommendations spread like wildfire. They soon became adapted in the civilian trauma community and almost reached the point of 'standard of care' for resuscitating severely injured patients. ${ }^{36}$ One of the most amazing aspects of the widespread acceptance of this 1:1 FFP/RBC regimen was the total absence of any measurements of procoagulants in the injured soldiers or injured civilians before or after the implementation of the $1: 1 \mathrm{FFP} / \mathrm{RBC}$ resuscitation regimen. ${ }^{34-36}$

\section{A 2:5 FFP/RBC Ratio restores Procoagulants}

Stimulated by the rapid acceptance of the military resuscitation formula, the author accessed a large prospectively stored database to assess the effect of the FFP/RBC ratio on a group of patients who were severely injured, had hypotension with a systolic pressure below 80 torr for an average of 47 minutes, and received an average of 16.4 units RBC, 4.2 units FFP, and 14.2 L BES during ED and OR resuscitation. ${ }^{37}$ A total of 32 patients were studied during operation at an average of 3.7 hours after injury. Measurements included fibrinogen (FI) as a monitor of the stable coagulation factors and both factor $\mathrm{V}(\mathrm{FV})$ and factor (FVIII) as monitors of the two labile factors. Both FV and FVIII were chosen to monitor the labile factors since FV is made totally by the liver and FVIII is a tripartite factor with only one portion synthesized in the liver. Also monitored were the standard coagulation times (PT, PTT and TT) in addition to fibrin degradation products (FSP), plasmin and monomers. ${ }^{37}$ 
Five of the 32 patients died on the operating table. Four of these five patients had no recordable blood pressure or pulse at the time of admission, did not respond to emergency department resuscitation and had a futile operation averaging 3.9 hours. ${ }^{37}$ During this period of time, they had a blood pressure below 80 torr for an average of 105 minutes. They received an average of 31 RBC units, 5 FFP units and $28 \mathrm{~L}$ BES. The low FFP/RBC ratio (0.19/1) reflected the desperate need to push RBCs in patients with uncontrolled rapid bleeding, hypotension and severe anemia associated with frequent runs of bradycardia. The procoagulant levels done three hours after injury demonstrated a low FI (90.6 $\mathrm{mg} / \mathrm{dl})$, low FV (25\%) and marginally low FVIII (38\%). ${ }^{37}$ They also had prolonged clotting times with a PT 6.5 seconds off normal, a PTT of 50.1 seconds and a TT of 12.5 seconds. These patients clearly died of uncontrolled bleeding in association with a coagulopathy due to the inability to get enough FFP infused at a time, when all intravenous lines were being used to infuse RBCs. One of the five deaths on the table had a prolonged operating time and possibly could have been salvaged had damage control been implemented after control of vascular injuries.

The remaining 26 patients studied during operation survived. They were severely injured with an admission systolic pressure of 80 torr and a pulse of 123 . They also had an average shock time of 35 minutes. These patients received 14.4 units RBC, 4.1 units FFP and 12.2 L BES during operation. The FFP/RBC ratio averaged 0.3 . With this 0.3 ratio, the clotting times were well within range of effective clotting. The average FI was $161 \mathrm{mg} / \mathrm{dl}$, the average FV was $52 \%$ and the average FVIII was $75 \%$ during the middle of operation. The clotting times and the coagulation factor levels improved at the time of the first postoperative study done 9 hours after operation.

A total of 53 patients including 22 of the 32 patients studied during operation had additional studies done an average of 8.4 hours after operation. These studies showed a continued improvement in the coagulation times so that the PT averaged 2.1 seconds off control and the PTT averaged 32 seconds. Likewise, the procoagulant levels improved with the FI being $202 \mathrm{mg} / \mathrm{dl}$, the FV being $64 \%$ and the FVIII being $102 \%$. Clearly, all of the patients who had an FFP/RBC ratio of $0.3: 1$ or better had adequate restoration of procoagulants with appropriate restoration of the clotting times. To date, this is the only study showing the correlation between the FFP/RBC resuscitation ratio and the restoration of standard clotting times and the procoagulant levels. Based on these data, one can conclude that there is no need for an $\mathrm{FFP} / \mathrm{RBC}$ resuscitation ratio greater than $2: 5$ in order to restore procoagulants to levels compatible with effective coagulation.

\section{High FFP/RBC Ratio worsens Shock Insult}

The second purported benefit of a high (1:1) FFP/RBC resuscitation ratio is that the enhanced oncotic force restores plasma volume and vital signs with less BES. This premise was studied in 316 severely injured patients requiring MT in whom the severity of hemorrhagic shock insult was judged by the duration of the postresuscitation fluid uptake period (phase II) and the BES needs, weight gain and hypoproteneimia seen in phase II. ${ }^{38}$

The 316 patients with MT presented with hypotension $(\mathrm{SBP}=81$ torr), tachycardia $(117 / \mathrm{min})$, and had an average shock time ( $\mathrm{SBP}<80$ torr) of 31 minutes. During operation for control of bleeding, they received 14.2 units RBC, 854 $\mathrm{ml}$ FFP (3.2 units) and 11.5 L BES. The subsequent fluid uptake phase averaged 29.2 hours during which they gained of average of $8.4 \mathrm{~kg}$ and had a SA of $2.0 \mathrm{gm} / \mathrm{dl}$. The phase II time, BES needs, weight gain and hypoproteinemia were correlated with SBP, P, shock time, RBC, FFP and BES given during operation along with the FFP/RBC, BES/RBC and $\mathrm{BES} / \mathrm{FFP}$ resuscitation ratios.

Using linear and logarithmic analyses, there were no significant correlations between SBP and pulse to either postresuscitation hypoalbuminemia or weight gain. There was a highly significant positive correlation between shock time, RBC units, FFP units and BES liters given during operation to both phase II weight gain and hypoproteinemia. There was no significant correlation between FFP/RBC, BES/RBC or BES/FFP to either the phase II hypoproteinemia or weight gain. The FFP/RBC during operation correlated directly and significantly $(p=0.001)$ with phase II duration and BES needs $(p=0.002)$. In contrast, the BES/RBC correlated inversely and significantly $(p<0.001)$ with phase II duration and BES needs.

Based on these findings, one can conclude that the total physiologic insult as judged by the extent of postresuscitation hypoalbuminemia and fluid sequestration is poorly predicted by admission SBP and pulse but is accurately predicted by the number of minutes that the SBP is below 80 torr and the OR administration of RBC, FFP and BES. Contrary to popular thinking, the FFP/RBC, correlates directly with duration and BES needs of phase II, whereas, the $\mathrm{BES} / \mathrm{RBC}$ correlates inversely with phase II duration and BES needs. This is just the opposite of what is being purported by the proponents of a 1:1 FFP/RBC resuscitation ratio. The mechanisms for these unexpected findings are currently being studied.

\section{DISCUSSION}

The past 50 years have seen many changes in the resuscitation of severely injured patients requiring MT. Certainly, there 
will be more changes as the science of coagulopathy expands and the new modalities for resuscitation evolve. Based upon the past 50 years of first-hand experience, the author recommends that the severely injured patient be initially resuscitated with BES. The BES should not be normal saline which has excessive chloride ion and is associated with acidosis and hyperchloremia. ${ }^{39}$ The author recommends that the initial BES resuscitation be done with a plasmalike fluid which truly represents a physiologic BES. ${ }^{39}$ The initial resuscitation should take place on the way to the operating room so that there can be rapid control of ongoing hemorrhage. When rapid operative intervention is precluded for one reason or another, the resuscitation should be limited to keeping the patient's systolic pressure between 80 and 90 torr in order to prevent 'popping the clot' facilitating continued hemorrhage which will cause coagulopathy. ${ }^{38}$ During operation, the patient should be resuscitated with RBCs in order to restore hemoglobin and BES in order to restore perfusion pressures and maintain plasma volume at a time, when the BES is moving in an obligatory manner into the interstitial fluid space and, to some degree, into the intracellular space. ${ }^{40}$ The addition of FFP should begin when it becomes obvious that a patient who has already been started on his fifth RBC unit has not achieved hemostasis. One may then continue at a ratio of $2: 4 \mathrm{FFP} / \mathrm{RBC}$ so that by the time $10 \mathrm{RBC}$ units are infused, the patient will have a 0.3:1 ratio. Continued resuscitation with a $2: 4 \mathrm{FFP} / \mathrm{RBC}$ ratio should be ongoing and supported by ongoing measurements of standard coagulation times. The use of supplemental platelets should be reserved to those patients who have received a minimum of ten transfusions, have evidence of clinical oozing or have a platelet count documented to be less than 50,000. The use of the newer monitors of platelet and procoagulant function, namely, thromboelastography, should be studied carefully but should not become the prime determinants as to when to give platelets or FFP until scientific correlations have been made between the results of thromboelastography and the elements that each portion of these tests are supposed to represent. ${ }^{41,42}$ At no time should colloids be added to the resuscitation regimen. The author eagerly looks forward to future scientific studies which will stimulate a modification of the above recommendations.

\section{REFERENCES}

1. Lucas CE. Evaluation and resuscitation of critically injured patients. S Afr J Surg 1976;15(3):97-109.

2. Lucas CE. Resuscitation of the injured patient: The three phases of treatment. Surg Clin N Am 1977;57(1):3-15.

3. Lucas CE, Ledgerwood AM. Clinical significance of altered coagulation tests after massive transfusion for trauma. Am Surg 1981;47(3):125-30.
4. McKay DG. Trauma and disseminated intravascular coagulation. J Trauma 1969;9:646-60.

5. McKay DG, Muller-Beghaus G. Therapeutic indications of disseminated intravascular coagulation. Am J Cardiol 1967;20:392.

6. Cafferata HT, Aggeler PM, Robinson AJ, Blaisdell FW. Intravascular coagulation in the surgical patient: Its significance in diagnosis. Am J Surg 1969;111:281-91.

7. Baker WF. Clinical aspects of disseminated intravascular coagulation: A clinician's point of view. Semin Thromb Hemost 1989;15:1-57.

8. Ali G, Kak M, Kumar M, Bali SK, et al. Acute renal failure following echiscarinatus (saw-scaled viper) envenomation. Indian J Nephrol 2004;14:177-81.

9. Blaisdell FW. Causes, prevention, and treatment of intravascular coagulation and disseminated intravascular coagulation. J Trauma Acute Care Surg 2012;72(6)1719-22.

10. Harrigan C, Lucas CE, Ledgerwood AM, et al. Serial changes in primary hemostasis after massive transfusion. Surgery 1985;98:836-43.

11. Harrigan C, Lucas CE, Ledgerwood AM. The effect of hemorrhagic shock on the clotting cascade in injured patients. J Trauma 1989;29:1416-22.

12. Heinback DM. Hemostasis in massively transfused trauma patients. In: Fresh Frozen Plasma: Indications and Risk. NIH Consensus Development Conference. Bethesda, MD 1984:3839.

13. Shires T, Cunningham JN, Barko CRF, et al. Alterations in cellular membrane function during hemorrhagic shock. Ann Surg 1972;176:288-95.

14. Cunningham JN Jr, Shires GT, Wagner IY. Changes in intracellular sodium and potassium content of red blood cells in trauma and shock. Am J Surg 1971;122:650-57.

15. Gaisford WD, Pandey N, Jensen CG, et al. Pulmonary changes in treated hemorrhagic shock. Am J Surg 1972;124:738-43.

16. Skillman JH, Parikh BM, Tanenbaum BJ. Pulmonary arterial venous admixture: Improvement with albumin and diuresis. Surg 1970;119:440-47.

17. Bouwman DL, Weaver DW, Vega J, et al. Effects of albumin on serum protein homeostasis after hypovolemic shock. J Surg Res 1978;24(4):229-34.

18. Weaver DW, Ledgerwood AM, Lucas CE, et al. Pulmonary effects of albumin resuscitation for severe hypovolemic shock. Arch Surg 1978;113:387-92.

19. Lucas CE, Weaver DW, Higgins RF, et al. Effects of albumin versus non-albumin resuscitation on plasma volume and renal excretory function. J Trauma 18(8):564-70.

20. Lucas CE, Ledgerwood AM, Higgins RF. Impaired salt and water excretion after albumin resuscitation for hypovolemic shock. Surgery 1979;86(4):544-49.

21. Johnson SD, Lucas CE, Gerrick SJ, et al. Altered coagulation after albumin supplements for treatment of oligemic shock. Arch Surg 1979;114(4):379-83.

22. Ledgerwood AM, Lucas CE. A review of studies on the effects of hemorrhagic shock and resuscitation on the coagulation profile. J Trauma 2003;54:5688-574.

23. Lucas CE, Ledgerwood Am. Physiology of colloid-supplemental resuscitation from shock. J Trauma 2003;54:S75-S81.

24. Lucas CE, Denis R, Ledgerwood AM, Grabow D. The effects of Hespan on serum and lymphatic albumin, globulin, and coagulant protein. Ann Surg 1988;207:416-20. 
25. Swisher SN. Overview of fresh frozen plasma. In: Fresh Frozen Plasma: Indications and Risk. NIH Consensus Development Conference. Bethesda, MD 1984:13-18.

26. Martin DJ, Lucas CE, Ledgerwood AM, et al. Fresh Frozen plasma supplement to massive red blood cell transfusion. Ann Surg 1985;202(4):505-11.

27. Lucas CE, Ledgerwood AM, Saxe JM, et al. Plasma supplementation is beneficial for coagulation during severe hemorrhagic shock. Am J Surg 1996;171:399-404.

28. Ledgerwood AM, Lucas CE. A review of studies on the effects of hemorrhagic shock and resuscitation on the coagulation profile. J Trauma 2003:54(5):S68-S74.

29. Boffard KD, Riou B, Warren B, et al. Recombinant factor VIIa as adjunctive therapy for bleeding control in severely injured trauma patients: Two parallel randomized, placebo-controlled, double-blind chemical trials. J Trauma 2005;59:8-15.

30. Howes DW, Stratford A, Stirling M, et al. Administration of recombinant factor VII decreases blood loss after blunt trauma in non-coagulopathic pigs. J Trauma 2007;62:311-15.

31. McVey JH, Boswell E, Mumford AD, et al. Factor VII deficiency and the FVII mutation database. Hum Mutat 2001;17:2-17.

32. Rizoli SB, Nascimento B Jr, Osman F, et al. Recombinant activated coagulation factor VII and bleeding trauma patients. J Trauma 2006;61:1419-25.

33. Knudson MM, Cohen MJ, Reidy R, et al. Trauma, transfusions, and use of recombinant factor VIIa: A multicenter case registry report of 380 patients from the Western Trauma Association. J Am Coll Surg 2011;212:87-95.
34. Holcomb JB, Jenkins D, Rhee P, et al. Damage control resuscitation: Directly addressing the early coagulopathy of trauma. J Trauma 2007;52:307-10.

35. Simmons JW, White CE, Eastridge BJ, et al. Impact of policy change on US Army combat transfusion practices. J Trauma 2010;69:S75-S80.

36. Holcomb JB, Wade CE, Michalek JE, et al. Increased plasma and platelet to red blood cell ratios improves outcome in 466 massively transfused civilian trauma patients. Ann Surg 2008;248:447-58.

37. Lucas CE, Ledgerwood AM. An FFP/RBC resuscitation regimen that restores procoagulants without causing ARDS. J Trauma Acute Care Surg 2012;72(4):821-27.

38. Lucas CE, Ledgerwood AM. A higher FFP/RBC resuscitation ratio prolongs the post shock fluid uptake phase and increases BES needs. Arch Surg (in press).

39. Chowdhury AH, Cox EF, Francis ST, Lobel DN. A randomized, controlled, double-dash blind crossover study on the effects of 2-L infusions of $0.9 \%$ saline and plasma-Lyte ${ }^{\circledR} 148$ on renal blood flow velocity and renal cortical tissue perfusion in healthy volunteers. Ann Surg 2008;256:18-24.

\section{ABOUT THE AUTHOR}

\section{Charles E Lucas}

Professor, Department of Surgery, Wayne State University, 4201 St Antoine Avenue, Room 2V, Detroit, MI 48201, United States e-mail: clucas@med.wayne.edu 